\title{
3 The intersection of Indigenous Data Sovereignty and Closing the Gap policy in Australia
}

\author{
Raymond Lovett, Roxanne Jones and Bobby Maher
}

\section{Introduction}

This chapter has three sections. The first describes the most significant change to Aboriginal and Torres Strait Islander legislation (and with it policy) in contemporary times - the 1967 Australian Constitution referendum - as the genesis to Aboriginal and Torres Strait Islander social policy change in Australia. We discuss the rationale at the time for the change to the Australian Constitution and highlight what the changes in Aboriginal policy arrangements brought about. The second outlines the development of Indigenous Data Sovereignty (IDS) in Australia and introduce the Closing the Gap policy (CTG) - the most recent major social policy development in Indigenous affairs of the last decade. The third and final section applies an assessment of the CTG in relation to IDS and Indigenous Data Governance (IDG). We conclude with guidance for the incorporation of IDS and IDG principles for future policy.

\section{Section 1: Contemporary Aboriginal and Torres Strait Islander legislation and policy}

Prior to 1967 , states and territories retained all legislative and therefore policy responsibility for Aboriginal and Torres Strait Islander Peoples as the Commonwealth was legislatively excluded from law making for the population (United Kingdom House of Commons, 1900).

In the early 1960s, an increase in Aboriginal and Torres Strait Islander voices drew attention to the lack of Indigenous rights in policy making and the impact this was having on people's lives. In 1962, the Federal Council for Aboriginal Advancement (FCAA) lobbied for a referendum to amend section 51 (xxvi) of the Australian Constitution and repeal section 127 of the Constitution, giving the Commonwealth Government law making power in Aboriginal affairs. The rationale for the amendments was to have consistency and applicability of laws and regulations across all states and territories regarding Aboriginal people (National Museum of Australia, 1962). The advocacy for changes to the Constitution by Indigenous lobby groups convinced the Commonwealth to propose what was to become the successful 1967 referendum (House of Representatives, 1967). 
The first change to the Australian Constitution, as a result of the referendum, was removal of wording from section 51 (xxvi) which read: The Parliament shall, subject to this Constitution, have power to make laws for the peace, order and good government of the Commonwealth with respect to:- (xxvi) The people of any race, other than the aboriginal race in any State, for whom it is deemed necessary to make special laws.(United Kingdom House of Commons, 1900, p. 19)

Section 51 (xxvi) was amended to: The Parliament shall, subject to this Constitution, have power to make laws for the peace, order and good government of the Commonwealth with respect to: - (xxvi) The people of any race in any State, for whom it is deemed necessary to make special laws. (United Kingdom House of Commons, 1900, p. 19)

The second change to the Australian Constitution was removal of section 127 completely. Section 127 stated: "In reckoning the numbers of the people of the Commonwealth, or of a State or other part of the Commonwealth, aboriginal natives shall not be counted" (United Kingdom House of Commons, 1900, p. 45).

There is evidence that indicates the removal of section 127 was justified on the basis that Aboriginal people could then be counted in the national official statistics - and this opened the way for data about Aboriginal people to inform policy (Gardiner-Garden, 1997). It is important to understand though, data had been collected on the number and distribution of Aboriginal people across the states long before 1967 as evidenced in Commonwealth census reports (Commonwealth of Australia, 1971).

\section{What happened after the constitutional change?}

The impact of the 1967 referendum increased Commonwealth government law making almost immediately. For example, less than one year after the changes to the Constitution, the States Grants (Aboriginal Advancement) Act 1968 was passed by parliament (House of Representatives, 1967). Over the next decade the States Grants (Aboriginal Advancement) Act became the primary method of Commonwealth involvement in Aboriginal affairs through the provision of finance for the states initially for "Aboriginal advancement" in the form of finances for housing, health and education. The finance provided appears to be based on an amount calculated on Aboriginal populations within each of the States (House of Representatives, 1968). While Aboriginal population information was available prior to the referendum, increased efforts in the counting of Aboriginal people increased as one result of the changes (Commonwealth of Australia, 1973). The repeal of section 127 together with changes to section 51 has had a profound effect on the making of Indigenous social policy through increased data about Aboriginal people in Australia. The labeling in Indigenous social policy has, since the referendum, evolved from assimilation to self-determination, self-management, reconciliation, practical reconciliation and the present CTG. The governance structures of Indigenous affairs and policy in Australia have been punctuated by the setting up and dismantling of several 
different administrative and consultative mechanisms; at times, these changes have been communicated as needing to change because of "failure". The contested nature of the best approach to governance in this space has contributed to a lot of uncertainty about direction across crucial policy areas such as socioeconomic independence and recognition of land and other rights. Despite this major shift in the language from an assimilationist agenda to the language of self-determination, there continues to be a limited ability for Indigenous Peoples in Australia to contribute to the policy agenda. One of the main barriers to taking the lead in the policy agenda is access to data for Aboriginal and Torres Strait Islander Peoples and communities to inform and therefore drive the policy agenda.

\section{Aboriginal and Torres Strait Islander social policy, political philosophy and data representation}

Social policy in Australia, including the CTG, and Indigenous policies before it, has been plagued by political philosophy tensions as evidenced in political statements and debates about Indigenous policy (Financial Review, 2018). The debates and approaches to policy frame Aboriginal people as passive policy recipients and often reinforce Indigenous Peoples as outsiders to the policy process. This is compounded when policies are reimagined over time with limited attention to the history of Indigenous Peoples' exclusion from the social and economic fabric of Australian society that was entrenched in past laws and policies. Data has been at the forefront of Indigenous policy re-engineering and these data are often interpreted through a political philosophy lens.

Policy in its simplest definition is a course or principle of action adopted or proposed by an organization, group or individual (Howlett \& Cashore, 2014). While there are various definitions of social policy, the common elements encapsulate actions that improve the social well-being of society, including actions that improve well-being among those who experience inequity (McClelland, 2014). An action or proposed action relies on information or an evidence base to inform the decision about a course of action. Information used in deciding the policy course of action comes from the compilation of data to produce a view of the issue at hand and how policy levers can be used to make positive change. A policy or course of action is often also informed and implemented according to an underlying political philosophy or political process. It is the case that the policy (course of action) considers both a technical and political process in the design process (Howlett \& Cashore, 2014).

In the political sense therefore, policy is the course of action or stance a political party or government is to pursue. Again, information is required to inform the course of action. But here, political philosophy plays a role in how policy is discussed, formulated and implemented. In Australia the overarching political philosophy is of a representative democracy. In a representative democracy, eligible people vote for candidates to carry out the business of governing on their behalf. It is the policies of parties that people vote for-in other words, it is the appeal 
of policies aligned with people's political philosophies that people vote for. The most common political philosophies include:

1. utilitarianism (takes a "morally" right action, based on the action that produces the greatest good)

2. egalitarianism (all persons have the same fundamental rights)

3. libertarianism (maximize political freedom and autonomy)

Underpinning philosophies are important in being able to recognize a course of action taken in social policy when made by governments.

\section{The political philosophy and policy nexus}

Political philosophy is crucial in policy processes as political philosophy reflects on how best to arrange the life of a society that includes political institutions and social practices (Miller, 1998). For example, the CTG aims to "Close the Gap in Indigenous disadvantage by improving outcomes between Indigenous and non-Indigenous Australians in the areas of life expectancy, health, education and employment" (COAG, 2008a). This policy is of equity of outcome (the opportunity to reach the same outcomes in life as non-Indigenous Australians is the stated policy objective). This policy objective has broad support within the general population with a majority of all Australians in the general community reporting governments must do more to address Indigenous disadvantage (Reconciliation Australia, 2019). However, there are underlying competing political philosophies as to how this should be achieved. Examples of this are seen in the Reconciliation barometer where two-thirds of responders report agreeing or being neutral on the topic of Aboriginal and Torres Strait Islander people being responsible for their own disadvantage (Reconciliation Australia, 2019).

There appear to be two prevailing political philosophies that dominate Indigenous social policy discussions and debate in Australia and are evidenced in many statements by political leaders-with statements providing clues to the underlying political philosophy. For example, recent statements by political leaders along the libertarian philosophy include: "if you have a go in this country, you get a go" (Financial Review, 2018) and are interpreted as - if you have the will and desire to achieve, you can achieve. Another example includes moralizing the right actions (utilitarianism): "get the kids to school, get the adults to work, and make communities safe" are promulgated as simple neutral statements of fact that will resolve inequality (Commonwealth of Australia, 2018). The predominance of liberalism and utilitarianism in Indigenous policy and particularly social policy continues despite the long and continuous calls by Indigenous Peoples locally and internationally for rights-based frameworks that are more aligned with an egalitarian framework (Human Rights and Equal Opportunity Commission, 2007; UN General Assembly, 2007). Both before and after the 1967 referendum, the political philosophy and Indigenous data nexus have been used to promulgate the trope of Indigenous people, families 
and communities as not having the will, capacity or desire to improve their situation. As a result, the State is required to step in and data (or a lack of data) has been used as the ultimate policy weapon, to justify extreme policy and legal intervention.

The Northern Territory Emergency Response intervention (NTER) is an example where decisions were placed in the hands of politicians, government officials and bureaucrats without consideration of the recommendations from the board of enquiry that conducted the review; this response was also made in the absence of data about child sexual abuse in Aboriginal communities, but with extensive data available about the life circumstances that contribute to violence including sexual violence across communities. The response was premised on the immediate need to ensure protection of children. The political philosophy guided the implementation of control measures within Aboriginal communities such as sending in the Army to conduct child welfare checks, quarantining welfare payments, banning alcohol sales and access to pornography in Aboriginal communities and to take control of Indigenous land tenure and access systems (leases and permits) (Maddison, 2008). To ensure the policy response could be enacted, suspension of the Racial Discrimination Act 1975 was required, leaving Aboriginal communities and people feeling disempowered and excluded from any decision-making process. Further, the NTER policy response was inconsistent with the approach advised within the Little Children Are Sacred report (Anderson \& Wild, 2007).

\section{Section 2: Indigenous Data Sovereignty and Closing the Gap policy in Australia}

The foundations of the IDS and IDG movement in Australia were and continue to be, fostered internationally. The embryonic phase of IDS organization in Australia was born at the initial meeting of a collective group of mostly Indigenous Peoples with concerns about Indigenous data that came together at an international event held in Canberra in 2015. The workshop resulted with a book being developed: Indigenous Data Sovereignty-Towards an Agenda (Kukutai \& Taylor, 2016). Since the seminal publication on IDS, there is a growing group of people becoming involved in IDS in Australia primarily through the formation of the Maiam nayri Wingara (MnW) IDS collective and the Indigenous Data Network (IDN). Foundation workshops of MnW and IDN were held in 2017 and 2018. The formation of the IDN was prompted by a workshop at the University of Melbourne. This workshop discussed the concepts of IDS and IDG and also highlighted where IDS and IDG were already occurring. The forum also focused on the management of "legacy data sets" and "orphaned data"(Maiam nayri Wingara Indigenous Data Sovereignty Collective, 2018a).

In June 2018, the MnW collective co-hosted a summit with the Indigenous Governance Institute, with the objective to develop IDS principles for Australia. One of the key aims of the Indigenous Data Sovereignty Summit was to progress IDS and IDG through developing shared understandings and initiating an Australian set of IDG protocols and principles. A communique which outlines 
the IDS principles was developed (Maiam nayri Wingara Indigenous Data Sovereignty Collective, 2018b).

Both groups were set up for specific reasons-MnW to establish principles to guide Indigenous leadership and governance in the Indigenous data ecosystem (Maiam nayri Wingara Indigenous Data Sovereignty Collective, 2018b) and IDN to assist Indigenous communities in developing the technical capability and resources to enable them to manage their data for community advancement (Indigenous Data Network, 2019). Both groups share Indigenous community advancement at their core.

\section{The Closing the Gap policy}

The 2005 Social Justice Report (Aboriginal and Torres Strait Islander Social Justice Commissioner, 2005) called for the Australian Government to commit to achieving health equality for Aboriginal and Torres Strait Islander Australians. In response to the Social Justice Report, the National Indigenous Health Equality Campaign commenced in 2006, now known as the Close the Gap campaign. The Close the Gap campaign launched by Oxfam was the "public face" of the National Indigenous Health Equality Campaign. The Close the Gap campaign is overseen by a steering committee that comprises over 40 national health organizations who are committed to addressing Aboriginal and Torres Strait Islander health equality. The National Indigenous Reform Agreement (NIRA), also known as Closing the Gap Strategy) is a Council of Australian Governments (COAG) agreement between the Commonwealth of Australia and the states and territories of Australia and was signed in 2007. The NIRA is based on "intergovernmental reforms to close the gap in Indigenous disadvantage"(COAG, 2008a).

COAG identified and endorsed six specific targets that they refer to as "The Building Blocks" to support the reforms aimed at Closing the Gap: early childhood; schooling; health; economic participation; healthy homes; safe communities; and governance and leadership. The core objectives of the NIRA are closing the life expectancy gap within a generation; halving the gap in mortality rates for Indigenous children under five within a decade; ensuring all Indigenous four-year-olds in remote communities have access to early childhood education within five years; halving the gap for Indigenous students in reading, writing and numeracy within a decade; halving the gap for Indigenous People aged 20-24 in Year 12 attainment or equivalent attainment rates by 2020; and halving the gap in employment outcomes between Indigenous and non-Indigenous Australians within a decade. In order to monitor and assess the progress toward achieving the core objectives of the NIRA , 27 performance indicators were developed "across seven domains of the Building Blocks for improving the gaps in disadvantage". The NIRA indicators were developed by COAG-an exclusive government body. The NIRA indicators are reported annually (Connors, 2011) through the Prime Minister's report to parliament, and often receive significant media coverage. 


\section{Section 3: Assessment of the Closing the Gap policy against Indigenous Data Sovereignty and governance principles}

The CTG originates in the shift in legislative responsibility from states and territories to the Commonwealth as a product of the 1967 referendum. This change ushered in major reforms to Indigenous social policy making that are reflected in contemporary Australia. The intent of the amendment to the Constitution was primarily to ensure consistency of Indigenous legislation and therefore policy nationally. Prior to Commonwealth powers in Indigenous affairs, the states and territories had legislative responsibility for Indigenous affairs, including counting where people lived. The most contemporary policy reforms in Australia's Indigenous affairs have been driven by a need for data to simply understand who Aboriginal and Torres Strait Islander People are and where the populations are distributed. The 1967 referendum and the changes following largely amounted to a regular and consistent Aboriginal and Torres Strait Islander population count through the census (Taylor, 2009). Moving beyond simply counting and understanding who the Aboriginal and Torres Strait Islander population are, IDS and IDG in Australia seek to guide the data ecosystem to meet the needs of the population for which the data are about.

Importantly, there is increasing recognition that IDS principles in government policy require consideration, including a cohesive national strategy through a coordinated approach to Indigenous data (Commonwealth of Australia, 2019). To assess how the current policy approach to Indigenous affairs in Australia is occurring in light of IDS, we have undertaken an assessment of how "Closing the Gap" would fare in relation to the application of the principles. This serves two purposes - the first is to promote the principles including their practical application in the context of Indigenous policy at the national level and the second is to guide social policy makers in how the Indigenous Data Sovereignty principles can be used to make good social policy based in IDS principles.

MnW Principle 1: Indigenous Peoples have the right to exercise control of the data ecosystem including creation, development, stewardship, analysis, dissemination and infrastructure.

MnW Principle 4: Indigenous Peoples have the right to data structures that are accountable to Indigenous peoples.

Indigenous involvement in Australian Indigenous policy making and data has been largely relegated to representation on advisory groups for predetermined actions. This includes a range of structures concerning the CTG implementation and the data ecosystems supporting policy. While this offers an opportunity for Aboriginal and Torres Strait Islander Peoples to contribute to contextual viewpoints on policy and what data should be collected and statistical outputs, it is a far cry from IDS and is actually setting the agenda. Over the years, advisory groups, reference groups, advisory councils and even legislative functions have morphed or been disbanded all together. The data space has not been immune: for example, the National Advisory Group on Aboriginal and Torres Strait Islander Health Data Information and Data (NAGATSIHD), who provided advice to the Australian Health Ministers Advisory Council on the improvement of government 
health information about Aboriginal and Torres Strait Islander Peoples (Kukutai \& Taylor, 2016) was disbanded in 2016. The development of agreements between Aboriginal and Torres Strait Islander Peoples and groups, the Commonwealth and state/territory governments concerning Indigenous health data governance principles and process are absent in Australia. There are few mechanisms for Aboriginal and Torres Strait Islander Peoples to lead or control data governance, other than at the local service or community level through organizations such as Aboriginal Community Controlled Health Organizations (ACCHOs).

In terms of accountability, the Australian National Audit Office asked if the Australian Government's contribution to CTG had been effectively monitored. The assessment states that "From 2008 to 2014 monitoring of the Australian Government's contribution towards Closing the Gap was only partially effective". Since 2015, monitoring has not been effective, as mechanisms for monitoring wholeof-government performance in Aboriginal and Torres Strait Islander affairs have ceased (The Auditor-General, 2019). The Closing the Gap Prime Minister's Report does not provide an objective assessment of contribution toward Closing the Gap.

Opportunities for IDG and IDS: most recently, the language in the CTG reports indicate the opportunity for greater control by Indigenous People: "priorities for the future involve creating more opportunities for shared decisionmaking, improving access to and collection of data to increase transparency" (Commonwealth of Australia, 2020, p. 9).

The opportunity for greater Indigenous control within the data ecosystems can come from lessons learned with other Indigenous populations. In Ontario, Canada, there is an agreement in place between the Ontario provincial government and the Chiefs of Ontario concerning data help by the State. A Data Governance Agreement serves to facilitate First Nations-engaged research and ensures that Indigenous Data Sovereignty principles are firmly established, including a grounding in the First Nation data principles of Ownership, Control, Access and Possession (OCAP®) (Schnarch, 2004). Through the agreement, any use of data held by the state that directly or indirectly identifies First Nations Peoples or communities is subject to First Nations governance processes. This ensures that all First Nations-specific analysis of state-held data is undertaken according to First Nations' collective priorities and applies Indigenous community-based research approaches.

In terms of data development, an important precedent was set at The United Nations Permanent Forum on Indigenous Issues (2006), with the United Nations Declaration on the Rights of Indigenous People declaration stating that: "Indigenous peoples will define their own understandings and visions of wellbeing from which indicators will be identified, and include the full participation of Indigenous peoples in the development of these indicators" (p. 15). Despite such declarations, in many countries (including Australia) policy development and application remains deeply rooted in improving Indigenous well-being, as it is perceived by the dominant (Western) non-Indigenous culture. This position is most clearly articulated in the framework underpinning the CTG suite of policies, where Indigenous outcomes are benchmarked against outcomes achieved by the non-Indigenous population 
(Commonwealth of Australia, 2020). The use of a non-Indigenous perspective of well-being in the design and application of Indigenous policy is fundamentally flawed, as it does not account for Indigenous ways of life. What is needed is an appreciation of Indigenous well-being, as perceived by the Indigenous population itself. With a clearer understanding of Indigenous well-being and its determinants, more appropriate policy, and ultimately better outcomes, will be able to be achieved for this population - with the mantra of data by us, for us.

The unfortunate outcome of the current metrics and reporting of these metrics is one of blame and of a problem that requires fixing (Fogarty, Bulloch, McDonnell, \& Davis, 2018; Walter, 2018) as one point of reference. There is hope, however. The most recent Commonwealth health policy at its core recognizes the importance of culture and how systemic racism impacts well-being (Commonwealth of Australia, 2015). While there is now recognition of these important constructs in social policy, metrics and who develops these is to be determined.

MnW Principle 2: Indigenous Peoples have the right to data that is contextual and disaggregated (available and accessible at individual, community and First Nations levels) and MnW Principle 3: Indigenous Peoples have the right to data that is relevant and empowers sustainable self-determination and effective self-governance.

The aim for Aboriginal and Torres Strait Islander populations to reach the same outcomes as the non-Indigenous population continues to ignore their cultural differences in aspirations and life values, and results in data that are focused on difference, disparity, disadvantage, dysfunction and deprivation (Walter, 2018). This is evident in the national CTG where the intent is to overcome disadvantage. The policy discussion (influenced by the statistical approach to reporting), however, often becomes politicized contributing to a narrative of failure and a waste of precious financial resources.

Much of the reporting of Indigenous data in Australia is at the national or jurisdictional level as it is for all Australians (Health \& Welfare, 2018b, 2019). However, the Aboriginal and Torres Strait Islander populations have long called for appropriate disaggregation to inform their own development needs (Walter \& Andersen, 2013) as well as access to or return of Indigenous data to communities for their use (Kukutai \& Taylor, 2016). There has been recent positive movement on disaggregation and decision making about data with shared prioritizing of the policy and data agenda (Commonwealth of Australia, 2020). There has also been increasing attention on different conceptualizations and operationalizing data items of meaning to Indigenous communities through Indigenous-led research and data development (Jones et al., 2018).

We also sought to understand how these CTG performance indicators were developed and ask the following questions: do they reflect community priorities and were the targets developed in partnership with Aboriginal and Torres Strait Islander Peoples? Sullivan (2011) describes how the indicators of progress against the CTG targets were unclear and no explanation is given as to how the performance indicators were developed, or importantly, how these indicators reference the seven "Building Blocks" that underpin the CTG and agreement 
between the states and the Commonwealth. The focus of outcomes of the original policy reforms underlying the CTG included tackle smoking ("the single biggest killer of Indigenous people"); healthy transition to adulthood; making Indigenous health everyone's business; primary healthcare service that can deliver; and fixing the gaps and improving the patient journey. Aboriginal and Torres Strait Islander Peoples have not been included in the priority setting process and local community priorities are not built into the targets and indicators.

To implement IDS Principles 2 and 3, data development of concepts important to Aboriginal and Torres Strait Islander Peoples requires further development and the return of Indigenous data could be achieved with further expansion of data governance agreements.

MnW Principle 5: Indigenous Peoples have the right to data that is protective and respects our individual and collective interests.

The overarching statistical methods used in the reporting of Indigenous policy agendas including the CTG predominantly focus on disadvantage, relative rates (gap measurement) and comparing Indigenous with non-Indigenous populations, particularly around life expectancy and health outcomes (Altman, 2009; Jordan, Bulloch, \& Buchanan, 2010).

Australian governments and policy makers rely heavily on data to shape and review policies and report on the progress of Indigenous outcomes. The approach to analysis of data often defaults to deficit framing. For example, the recent reductions observed within the last decade of a 10 percent decline in Indigenous smoking rates have instead been reported as a failure because there has also been a similar level of decline within the non-Indigenous population and therefore the decline within the Indigenous population relative to the non-Indigenous population has not changed (Health \& Welfare, 2018a, 2018b). However, looking at the data within the Indigenous population (Lovett, Thurber, Wright, Maddox, \& Banks, 2017) where between 2004-2005 and 2014-2015 there were significant reductions in smoking prevalence, with an estimated 35,000 fewer Aboriginal and Torres Strait Islander adults smoking daily (Lovett et al., 2017). While prevalence across Aboriginal and Torres Strait Islander Peoples remain high, there are fewer young adults taking up smoking which portrays positive gains across the population and a good news story for the nation (Lovett et al., 2017). Further, this piece of work reflects the importance of the national policy Tackling Indigenous Smoking program as an important contributor to reducing tobacco smoking. It also shows the relevance of analysis within a population to build sound policy. In contrast, the CTG continues to focus on comparisons between Indigenous and non-Indigenous Peoples rather than absolute change within the Aboriginal and Torres Strait Islander population which shows improvement through reduced prevalence of some health conditions and harmful health behaviors. There is a risk of perpetuating the myth that Aboriginal and Torres Strait Islander health and well-being is not improving which does harm (i.e., is not protective) (Harris, 2020).

This analysis also sought to understand how IDS was involved in the development phase of the CTG. The NIRA states: "To date, engagement with Aboriginal and Torres Strait Islander people on the development of the Closing the Gap agenda 
has been at a very broad level" (COAG, 2008a). There was an Indigenous engagement strategy written within the agreement; however, this is related to the implementation of programs, rather than the development of the reforms. There are also jurisdictional Indigenous advisory groups, representative bodies, sector-specific advisory groups and Indigenous organization-based advisory structures that support Closing the Gap (Thorpe, Arabena, Sullivan, Silburn, \& Rowley, 2016).

The metric that the Closing the Gap strategy focuses on is flawed and contributes to the deficit discourse around Aboriginal and Torres Strait Islander health. The Closing the Gap strategy was based on the comparison of Aboriginal and Torres Strait Islander Peoples relative to non-Indigenous People. Accordingly, in order to "close the gap", Aboriginal and Torres Strait Islander health needs to improve faster than non-Indigenous health. The gap between Aboriginal and Torres Strait health and non-Indigenous health is relevant, though measurements of progress and improvement within the Aboriginal and Torres Strait Islander population is arguably more important. Changing the conversation from "not on track", to progress within the population can have positive effects on individuals and communities alike and is aligned with protecting Indigenous interests.

\section{Opportunities for policy: enhancing Indigenous policy through IDS and IDG through a Commonwealth Indigenous data governance agreement}

There have been a number of policy developments in Australia in recent times that have potential to foster the application of IDS and IDG. The appetite to reform the data landscape in Australia creates both opportunity and warning. For example, the Murray review in 2014 recommended the following: "Review the costs and benefits of increasing access to and improving the use of data, taking into account community concerns about appropriate privacy protections" (pp. xxiv). The review further highlighted that this recommendation warranted more in-depth discussion. This recommendation was tasked to the Productivity Commission and was the basis for the Productivity Commission's Inquiry into Data Availability and Use that sought to examine mechanisms to make better use of data holdings of the Government. The recommendations included major reforms to data access and use including through the creation of new legislation and systems to make data more available (Productivity Commission, 2017). While there was no consideration of IDS or IDG within the review (despite submissions being made on Indigenous Data Sovereignty), consultations concerning the development of the Data Sharing and Release Legislation has incorporated views from both the $\mathrm{MnW}$ and the IDN resulting in ensuring Indigenous Data Sovereignty and governance aspects being incorporated within the new legislation as the report highlighted:

We heard the need to pay close attention to matters related to Indigenous data. We heard concerns relating to Indigenous access to Indigenous data and Indigenous data sovereignty. The National Indigenous Australians Agency is in the early stages of developing a more effective approach to Indigenous 
data, including a possible whole-of-government Indigenous data strategy, and we are working together to get it right.

(Commonwealth of Australia, 2019, p. 7)

While the proposed legislative change is yet to occur, there is an opportunity to embed IDS or at a minimum IDG within this framework.

Our examination of the intersection of IDS and IDG in the CTG establishment and revision, highlights yet again an inability of the policy apparatus to engage in the discussion about what it is we are trying to improve and how we should measure and monitor Indigenous progress or achievement. We find that CTG, like other major Indigenous reform agendas, was born out of initial pressure from Indigenous groups and allies that forced governments into action.

Despite the initial CTG "targets" being focused on the population they were meant to be monitoring, implementation of data-monitoring processes without application of IDS and IDG have contributed to what is now understood by the polity and general public - that CTG is a policy failure. This result has occurred because Indigenous data frameworks are based on a comparative deficit-based analysis with the "normative" reference of non-Indigenous Australians as the optimal definition of what a "good life" is. Indigenous Peoples have stepped up once again to influence reforms both in the refresh of the CTG and in the major shift occurring in the broader data reform space to influence change more broadly.

\section{Conclusion}

The narrative of policies such as the CTG, continues to be directed by politicians of the day and their political agendas. Policy reform linking "statistical equality" implies that policy is driven by statistical comparisons between Aboriginal and Torres Strait Islander Peoples and the non-Indigenous population. The process of policy making, including data development for policy reform, therefore rarely includes Aboriginal and Torres Strait Islander perspectives, values and principles. Using comparable statistics to shape policies brings a focus on the deficit narrative. Government reports such as the Prime Minister's Closing the Gap Report and the Overcoming Indigenous Disadvantage Report continue to frame Aboriginal and Torres Strait Islander health and well-being through an illhealth lens of disadvantage and failure to reach statistical equality that omits an Indigenous worldview, aspirations or perspectives.

As a post-script, Indigenous affairs and policy in Australia are undergoing what is deemed in policy circles as a "refresh". The original 20-year Closing the Gap reporting cycle has made it apparent to all, including policy makers that Indigenous policy frameworks, as they are currently construed, and as demonstrated in this chapter, are not working. The use of data via the annual reporting against CTG targets is what has made what Aboriginal and Torres Strait communities and organizations have been saying for years, that current policy prescriptions were ineffective at best, undeniable. The other key message to governments and 
their policy makers, that Aboriginal and Torres Strait Islander communities and organizations themselves are best placed to shape and implement policy has also resonated.

In 2019, the Coalition of the Peaks, a representative body of around 50 Aboriginal and Torres Strait Islander community-controlled peak organizations entered a formal partnership with $\mathrm{COAG}$, to share decision making on CTG. According to this agreement, over the next ten years CTG measures will be joint actions with the voices of Aboriginal and Torres Strait Islander Peoples central in all decision making (NACCHO, n.d.). After a year of Indigenous community consultation, this process will get underway in mid-2020. The question will be whether the new partnership on CTG will provide opportunities to embed Indigenous Data Sovereignty and governance processes that enhance control of data by Indigenous Peoples for the benefit of Indigenous Peoples and communities.

\section{References}

Aboriginal and Torres Strait Islander Social Justice Commissioner. (2005). Social Justice Report 2005. Retrieved from Sydney: https://goo.g1/HfhQY9.

Altman, J.C. (2009). Beyond Closing the Gap: Valuing Diversity in Indigenous Australia (Vol. 54). Citeseer.

Anderson, P., \& Wild, R. (2007). Ampe Akelyernemane Meke Mekarle "Little Children are Sacred" Report of the Northern Territory Board of Inquiry into the Protection of Aboriginal Children from Sexual Abuse. Darwin Retrieved from ISBN:978-0-9803874-1-4.

COAG. (2008a). National Indigenous Reform Agreement (Closing the Gap). Retrieved from http://www.federalfinancialrelations.gov.au/content/npa/health/_archive/Ind igenous-reform/national-agreement_sept_12.pdf.

Commonwealth of Australia. (1971). Census of Population and Housing, 30 June 1966, Part 11. Race. Canberra, Western Australia: William C. Brown, Governement Printer.

Commonwealth of Australia. (1973). Characteristics of the Aboriginal and Torres Strait Islander Population. Union Offset Co. Pty. Ltd.

Commonwealth of Australia. (2015). National Aboriginal and Torres Strait Islander Health Plan 2013-2023 (978-1-74241-980-0). Retrieved from Canberra: https://ww w1.health.gov.au/internet/main/publishing.nsf/content/B92E980680486C3BCA257 BF0001BAF01/\$File/health-plan.pdf.

Commonwealth of Australia. (2018). Parliamentary Debates: House of Representatives Official Hansard. Canberra: Commonwealth of Australia.

Commonwealth of Australia. (2019). Data Sharing and Release Legislative Reforms Discussion Paper. Canberra: Commonwealth of Australia.

Commonwealth of Australia. (2020). Closing the Gap Report 2020. Canberra: Commonwealth of Australia.

Commonwealth of Australia Constitution Act [Australia]. (1900).

Connors, K. (2011). Reporting Against the National Indigenous Reform Agreement: What Have We Learnt So Far? Paper presented at the Indigenous Education: Pathways to Success. https://research.acer.edu.au/cgi/viewcontent.cgi?article=1119\&context=r esearch_conference. 
Constitutional alteration (Aboriginals) Bill. (1967). Second Reading Speech, March 1, 1967.

Financial Review (Producer). (2018, 29/01/2020). Transcript of New Prime Minister Scott Morrison's First Press Conference. [Online Newspaper].

Fogarty, W., Bulloch, H., McDonnell, S., \& Davis, M. (2018). Deficit Discourse and Indigenous Health: How Narrative Framings of Aboriginal and Torres Strait Islander People Are Reproduced in Policy (p. xii). Melbourne: The Lowitja Institute.

Gardiner-Garden, J. (1997). The Origin of Commonwealth Involvement in Indigenous Affairs and the 1967 Referendum. Canberra: Department of the Parliamentary Library. Retrieved from http://www.aph.gov.au/library/pubs/bp/1996-97/97bp11.htm.

Harris, R. (2020, February 12, 2020). Bid to close the gap on indigenous benchmarks has "failed". Sydney Morning Herald. Retrieved from https:/www.smh.com.au/politics/ federal/bid-to-close-the-gap-on-Indigenous-benchmarks-has-failed-20200211-p53zug .html.

Health, A. I. o., \& Welfare. (2018a). Australia's Health 2018. Retrieved from Canberra: https://www.aihw.gov.au/reports/australias-health/australias-health-2018.

Health, A. I. o., \& Welfare. (2018b). Closing the Gap Targets: 2017 Analysis of Progress and Key Drivers of Change. Retrieved from Canberra: https://www.aihw.gov.au/report s/Indigenous-australians/closing-the-gap-targets-2017-analysis-of-progress.

Health, A. I. o., \& Welfare. (2019). Australia's Welfare 2019: In Brief. Retrieved from Canberra: https://www.aihw.gov.au/reports/australias-welfare/australias-welfare2019-in-brief.

Howlett, M., \& Cashore, B. (2014). Conceptualizing public policy. In I. Engeli, \& C.R. Allison (Eds.), Comparative Policy Studies: Research Methods Series. London: Palgrave Macmillan.

Human Rights and Equal Opportunity Commission. (2007). A Human Rights Based Approach is Vital to Address the Challenges in Indigenous Communities. Press Release.

Indigenous Data Network. (2019). The Indigenous Data Network: Position Paper. Melbourne: Indigenous Data Network.

Jones, R., Thurber, K.A., Chapman, J., D’Este, C., Dunbar, T., Wenitong, M., ... \& Lovett, R. (2018). Study protocol: our cultures count, the Mayi Kuwayu study, a national longitudinal study of aboriginal and Torres Strait Islander wellbeing. BMJ Open, 8(6), e023861. doi:10.1136/bmjopen-2018-023861.

Jordan, K., Bulloch, H., \& Buchanan, G. (2010). Statistical equality and cultural difference in Indigenous wellbeing frameworks: a new expression of an enduring debate. Australian Journal of Social Issues, 45(3), 333-362.

Kukutai, T., \& Taylor, J. (2016). Indigenous Data Sovereignty: Toward an Agenda. Canberra: ANU Press.

Lovett, R., Thurber, K., Wright, A., Maddox, R., \& Banks, E. (2017). Deadly progress: changes in Australian Aboriginal and Torres Strait Islander adult daily smoking, 20042015. Public Health Research \& Practice, 27(5), 2751742.

Maddison, S. (2008). Indigenous autonomy matters: what's wrong with the Australian government's "intervention" in Aboriginal communities. Australian Journal of Human Rights, 14(1), 41-61. doi:10.1080/1323238X.2008.11910845.

Maiam nayri Wingara Indigenous Data Sovereignty Collective. (2018a). Data for Governance: Governance for Data. Retrieved from Canberra: https://static1.squarespa ce.com/static/5b3043afb40b9d20411f3512/t/5b70e7742b6a28f3a0e14683/153412594 6810/Indigenous+Data+Sovereignty+Summit+June+2018+Briefing+Paper.pdf. 
Maiam nayri Wingara Indigenous Data Sovereignty Collective. (2018b). Indigenous Data Sovereignty Communique. Retrieved from Canberra: https://static1.squarespace.com /static/5b3043afb40b9d20411f3512/t/5b6c0f9a0e2e725e9cabf4a6/1533808545167/ Communique\%2B-\%2BIndigenous\%2BData\%2BSovereignty\%2BSummit.pdf.

McClelland, A. (2014). Part 1: Introduction to Social Policy. South Melbourne: Oxford University Press Australia.

Miller, D. (1998). Political Philosophy. Retrieved from https://www.rep.routledge.com/ articles/overview/political-philosophy/v-1 doi:10.4324/9780415249126-S099-1.

NACCHO. (n.d.). Coalition of the Peaks. https://www.naccho.org.au/programmes/coalitio n-of-peaks/.

National Museum of Australia. (1962). Collaborating for Indigenous Rights: National Petition Campaign, 1962-63. Retrieved from http://Indigenousrights.net.au/subsectio n.asp?ssID=25.

Productivity Commission. (2017). Data Availability and Use. Canberra: Productivity Commission.

Reconciliation Australia. (2019). Australian Reconciliation Barameter 2018. Canberra: Reconciliation Australia.

Schnarch, B. (2004). Ownership, Control, Access, and Possession (OCAP) or selfdetermination applied to research: a critical analysis of contemporary first nations research and some options for first nations communities. Journal of Aboriginal Health, 1, 80-95.

States Grants (Aboriginal Advancement) Act. (1968).

Taylor, J. (2009). Indigenous demography and public policy in Australia: population or peoples? Journal of Population Research, 26(2), 115-130.

The Auditor-General. (2019). Closing the Gap. Canberra: Auditor-General Report.

Thorpe, A., Arabena, K., Sullivan, P., Silburn, K., \& Rowley, K. (2016). Engaging First Peoples: A Review of Government Engagement Methods for Developing Health Policy. Retrieved from Melbourne: https://www.lowitja.org.au/content/Document/Lowitja -Publishing/Engaging-First-Peoples.pdf.

UN General Assembly. (2007). United Nations Declaration on the Rights of Indigenous Peoples: Resolution/Adopted by the General Assembly (Vol. A/RES/61/295). UN General Assembly.

Walter, M. (2018). The voice of indigenous data: beyond the markers of disadvantage. Griffith Review, 2018(60), 256.

Walter, M., \& Andersen, C. (2013). Indigenous Statistics A Quantitative Research Methodology. New York, NY: Routledge. 